\title{
ON THE COMPLETE CONVERGENCE FOR WEIGHTED SUMS OF EXTENDED NEGATIVELY DEPENDENT RANDOM VARIABLES
}

\author{
Yongfeng Wu, MingQing Zhai And JiangYan Peng
}

Abstract. The authors investigate the complete convergence for weighted sums of extended negatively dependent (END) random variables. The main results obtained in the paper extend and improve the corresponding result of Zarei and Jabbari [Zarei, H., Jabbari, H., 2011. Complete convergence of weighted sums under negative dependence. Stat. Papers, 52, 413-418].

Mathematics subject classification (2010): 60F15.

Keywords and phrases: Extended negatively dependent, weighted sums, complete convergence.

\section{REFERENCES}

[1] Ebrahimi, N., Ghosh, M., Multivariate negative dependence, Commun. Stat., Theory Methods, 10 (1981), 307-337.

[2] Liu, L., Precise large deviations for dependent random variables with heavy tails, Statist. Probab. Lett., 79 (2009), 1290-1298.

[3] Johg-Dev, K., Proschan, F., Negative association of random variables with applications, Ann. Stat., 11 (1983), 286-295.

[4] TAylor, R. L., Patterson, R. F., Bozorgnia, A., A strong law of large numbers for arrays of rowwise negatively dependent random variables, Stochastic Anal. Appl. 20 (2002), 643-656.

[5] Volodin, A., On the Kolmogorov exponential inequality for negatively dependent random variables, Pakistan J. Stat. 18 (2002), 249-253.

[6] Amini, D. M., Bozorgnia, A., Complete convergence for negatively dependent random variables, J. Appl. Math. Stochastic Anal., 16 (2003) 121-126.

[7] Volodin, A., Cabrera, M. O., Hu, T. C., Convergence rate of the dependent bootstrapped means, Theory Probab. Appl. 50 (2006), 337-346.

[8] GAN, S. X., CHEN, P. Y., Strong convergence rate of weighted sums for NOD sequences, Acta Math. Sci., Ser. A, 28 (2008), 283-290 (in Chinese).

[9] WU, Q. Y., Complete convergence for negatively dependent sequences of random variables, J. Inequal. Appl., (2010) doi:10.1155/2010/507293.

[10] WU, Y. F., ZHU, D. J., Convergence properties of partial sums for arrays of rowwise negatively orthant dependent random variables, J. Korean Stat. Soc., 39 (2010), 189-197.

[11] Qiu, D. H., Chan, K. C., Antonini, R. G., Volodin, A., On the strong rates of convergence for arrays of rowwise negatively dependent random variables, Stochastic Anal. Appl., 29 (2011), 375385.

[12] Ko, M. H., KIM, T. S., Almost sure convergence for weighted sums of negatively orthant dependent random variables, J. Korean Math. Soc., 42 (2005), 949-957.

[13] Ko, M. H., HAN, K. H., KIM, T. S., Strong laws of large numbers for weighted sums of negatively dependent random variables, J. Korean Math. Soc., 43 (2006), 1325-1338.

[14] WANG, X. J., Hu, S. H., Volodin, A., Strong limit theorems for weighted sums of NOD sequence and exponential inequalities, Bull. Korean Math. Soc., 48 (2011), 923-938.

[15] Wu, Y. F., Ordóñez Cabrera, M., Volodin, A., On limiting behavior for arrays of rowwise negatively orthant dependent random variables, J. Korean Stat. Soc., 42 (2013), 61-70.

[16] Chen, Y. Q., Chen, A. Y., NG, K. W., The strong law of large numbers for extended negatively dependent random variables, J. Appl. Prob., 47 (2010), 908-922. 
[17] Wu, Y. F., GuAn, M., Convergence properties of the partial sums for sequences of END random variables, J. Korean Math. Soc., 49 (2012), 1097-1110.

[18] Qiu, D. H., Chen, P. Y., Antonini, R. G., Volodin, A., On the complete convergence for arrays of rowwise extended negatively dependent random variables, J. Korean Math. Soc., 50 (2013), 379392.

[19] WAng, S. J., WAng, X. J., Precise large deviations for random sums of END real-valued random variables with consistent variation, J. Math. Anal. Appl., 402 (2013), 660-667.

[20] Zhang, G. H., Complete convergence for Sung's type weighted sums of END random variables, J. Inequal. Appl. (2014), 353.

[21] WU, Y. F., PENG, J. Y., HU, T. C., Limiting behaviour for arrays of row-wise END random variables under conditions of h-integrability, Stochastics, 87 (2015), 409-423.

[22] SHEn, A. T., Volodin, A., Weak and strong laws of large numbers for arrays of rowwise END random variables and their applications, Metrika (2017), 10.1007/s00184-017-0618-z.

[23] Hsu, P. L., Robiins, H., Complete convergence and the law of large numbers, Proc. Nat. Acad. Sciences., 33 (1947), 25-31.

[24] Zarei, JabBARI, Complete convergence of weighted sums under negative dependence, Stat. Papers, 52 (2011), 413-418.

[25] Shen, A. T., Probability inequalities for END sequence and their applications, J. Inequal. Appl. (2011), 98.

[26] Stout, W. F., Almost sure convergence, (1974) Academic Press, New York.

[27] Zhang, G. H., Complete convergence for Sung's type weighted sums of END random variables, J. Inequal. Appl. (2014), 353. 